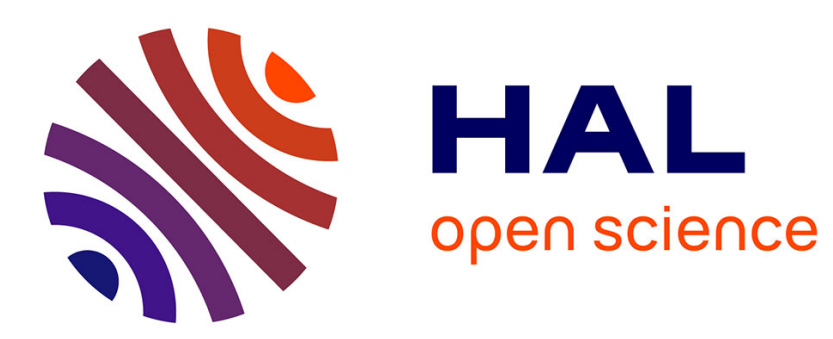

\title{
Gasification of Wood Char in Single and Mixed Atmospheres of $\mathrm{H} 2 \mathrm{O}$ and $\mathrm{CO} 2$
}

J. P. Tagutchou, L. van De Steene, Francisco Javier Escudero Sanz, Sylvain Salvador

\section{- To cite this version:}

J. P. Tagutchou, L. van De Steene, Francisco Javier Escudero Sanz, Sylvain Salvador. Gasification of Wood Char in Single and Mixed Atmospheres of H2O and CO2. Energy Sources, Part A, 2013, 35 (13), pp.1266-1276. 10.1080/15567036.2010.542438 . hal-01688104

\section{HAL Id: hal-01688104 https://hal.science/hal-01688104}

Submitted on 4 Apr 2018

HAL is a multi-disciplinary open access archive for the deposit and dissemination of scientific research documents, whether they are published or not. The documents may come from teaching and research institutions in France or abroad, or from public or private research centers.
L'archive ouverte pluridisciplinaire HAL, est destinée au dépôt et à la diffusion de documents scientifiques de niveau recherche, publiés ou non, émanant des établissements d'enseignement et de recherche français ou étrangers, des laboratoires publics ou privés. 


\title{
Gasification of Wood Char in Single and Mixed Atmospheres of $\mathrm{H}_{2} \mathrm{O}$ and $\mathrm{CO}_{2}$
}

\author{
J. P. Tagutchou, ${ }^{1}$ L. Van de steene, ${ }^{1}$ F. J. Escudero Sanz, ${ }^{2}$ and S. Salvador ${ }^{2}$ \\ ${ }^{1}$ CIRAD, UR 42 Biomasse Energie, Montpellier, France \\ ${ }^{2}$ Ecole des Mines d'Albi, Centre RAPSODEE, Campus Jarlard, AlbiFrance
}

\begin{abstract}
In gasification processes, char- $\mathrm{H}_{2} \mathrm{O}$ and char- $\mathrm{CO}_{2}$ are the main heterogenous reactions that are responsible for carbon conversion into $\mathrm{H}_{2}$ and $\mathrm{CO}$. These two reactions are generally looked at independently without considering interactions between them. The objective of this work was to compare kinetics of each reaction alone to kinetics of each reaction in a mixed atmosphere of $\mathrm{H}_{2} \mathrm{O}$ and $\mathrm{CO}_{2}$. A char particle was gasified in a macro thermo gravimetry reactor at $900^{\circ} \mathrm{C}$ successively in $\mathrm{H}_{2} \mathrm{O} / \mathrm{N}_{2}, \mathrm{CO}_{2} / \mathrm{N}_{2}$, and $\mathrm{H}_{2} \mathrm{O} / \mathrm{CO}_{2} / \mathrm{N}_{2}$ atmospheres.
\end{abstract}

Keywords: biomass, gasification, kinetics, mixed atmosphere, reactivity

\section{INTRODUCTION}

The process of biomass conversion to syngas $\left(\mathrm{H}_{2}+\mathrm{CO}\right)$ involves a number of reactions. The first step is drying and devolatilization of the biomass, which leads to the formation of gas (noncondensable species), tar (gaseous condensable species), and a solid residue called char. Gas and tar are generally oxidized to produce $\mathrm{H}_{2} \mathrm{O}$ and $\mathrm{CO}_{2}$.

The solid residue (the subject of this work) is converted to produce syngas $\left(\mathrm{H}_{2}+\mathrm{CO}\right)$ thanks to the following heterogeneous reactions:

$$
\begin{aligned}
\mathrm{C}+\mathrm{H}_{2} \mathrm{O} & \rightarrow \mathrm{CO}+\mathrm{H}_{2}, \\
\mathrm{C}+\mathrm{CO}_{2} & \rightarrow 2 \mathrm{CO} \\
\mathrm{C}+\mathrm{O}_{2} & \rightarrow \mathrm{CO} / \mathrm{CO}_{2} .
\end{aligned}
$$

Many studies have been conducted on char gasification in reactive $\mathrm{H}_{2} \mathrm{O}, \mathrm{CO}_{2}$, or $\mathrm{O}_{2}$ atmospheres. The reactivity of char during gasification processes depends on the reaction temperature and on the concentration of the reactive gas. Additionally, these heterogeneous reactions are known to be surface reactions, involving a so-called "reactive surface." While the role of temperature and reactive gas partial pressure are relatively well understood, clearly defining and quantifying the reactive surface remains a challenge. The surface consists of active sites located at the surface of

Address correspondence to Dr. L. Van de steene, CIRAD, 42 Biomasse Energie, TA B 42/16, 73, Avenue J.-F. Breton, Montpellier 34398, France. E-mail: steene@cirad.fr 
pores where the adsorption/desorption of gaseous molecules takes place. The difficulty involved in determining this surface can be explained by a number of physical and chemical phenomena that play an important role in the gasification process:

(i) The whole porous surface of the char may not be accessible to the reactive gas, and may itself not be reactive. The pore size distribution directly influences the access of reactive gas molecules to active sites (Roberts and Harris, 2006). It has been a common practice to use the total specific surface area measured using the standard BET test as the reactive surface. However, it has been established that a better indicator is the surface of only pores that are larger than several $\mathrm{nm}$ or tens of nm (Commandré et al., 2002).

(ii) As the char is heated to high temperatures, a reorganization of the structure occurs. The concentration of available active sites of carbon decreases and this has a negative impact on the reactivity of the char. This phenomenon is called thermal deactivation.

(iii) The minerals present in the char have a catalytic effect on the reaction and help increase the reactivity of the char. Throughout the gasification process, there is a marked increase in the mass fraction of catalytic elements contained in the char with a decrease in the mass of the carbon.

Due to the complexity of the phenomena and the difficulty to distinguish the influence of each phenomenon on reactivity, a surface function (referred to as SF in this article) is usually introduced in models to describe the gasification of carbon and to globally account for all of the physical phenomenon (Sorensen et al., 1996; Gobel et al., 2001).

While single $\mathrm{H}_{2} \mathrm{O}$ and $\mathrm{CO}_{2}$ atmospheres have been extensively studied, only a few authors have studied the gasification of a charcoal biomass in mixed atmospheres.

Kinetic model classically proposed for the gasification of carbon residues is as follows:

$$
\frac{d m(t)}{d t}=-R(t) \cdot m(t) .
$$

The reactivity of charcoal with a reactant $j$ is often split into intrinsic reactivity $r_{j}$, which only depends on temperature $T$ and partial pressure $p$ of the reactive gas, and the surface function $F$ :

$$
R(t)=F(X(t)) \cdot r_{j}(T \cdot p) .
$$

As discussed above, the surface function $F$ depends on many phenomena. In a simplifying approach, many authors express it as a function of the conversion $X$.

\section{METHODOLOGY}

Using a thermogravimetry (macro-TG) apparatus, gasification of char particles was characterized in three different reactive atmospheres: single $\mathrm{H}_{2} \mathrm{O}$ atmosphere, single $\mathrm{CO}_{2}$ atmosphere, and a mixed atmosphere containing both $\mathrm{CO}_{2}$ and $\mathrm{H}_{2} \mathrm{O}$.

\subsection{Experimental Set-up}

The macro-TG reactor used in this work is described in detail in Mermoud et al. (2006) and is presented in Figure 1. It consists of positioning several charcoal particles in a grid basket inside the reactor at atmospheric pressure. The reactor is swept by the oxidizing agent $-\mathrm{H}_{2} \mathrm{O}$ or $\mathrm{CO}_{2}$ in 


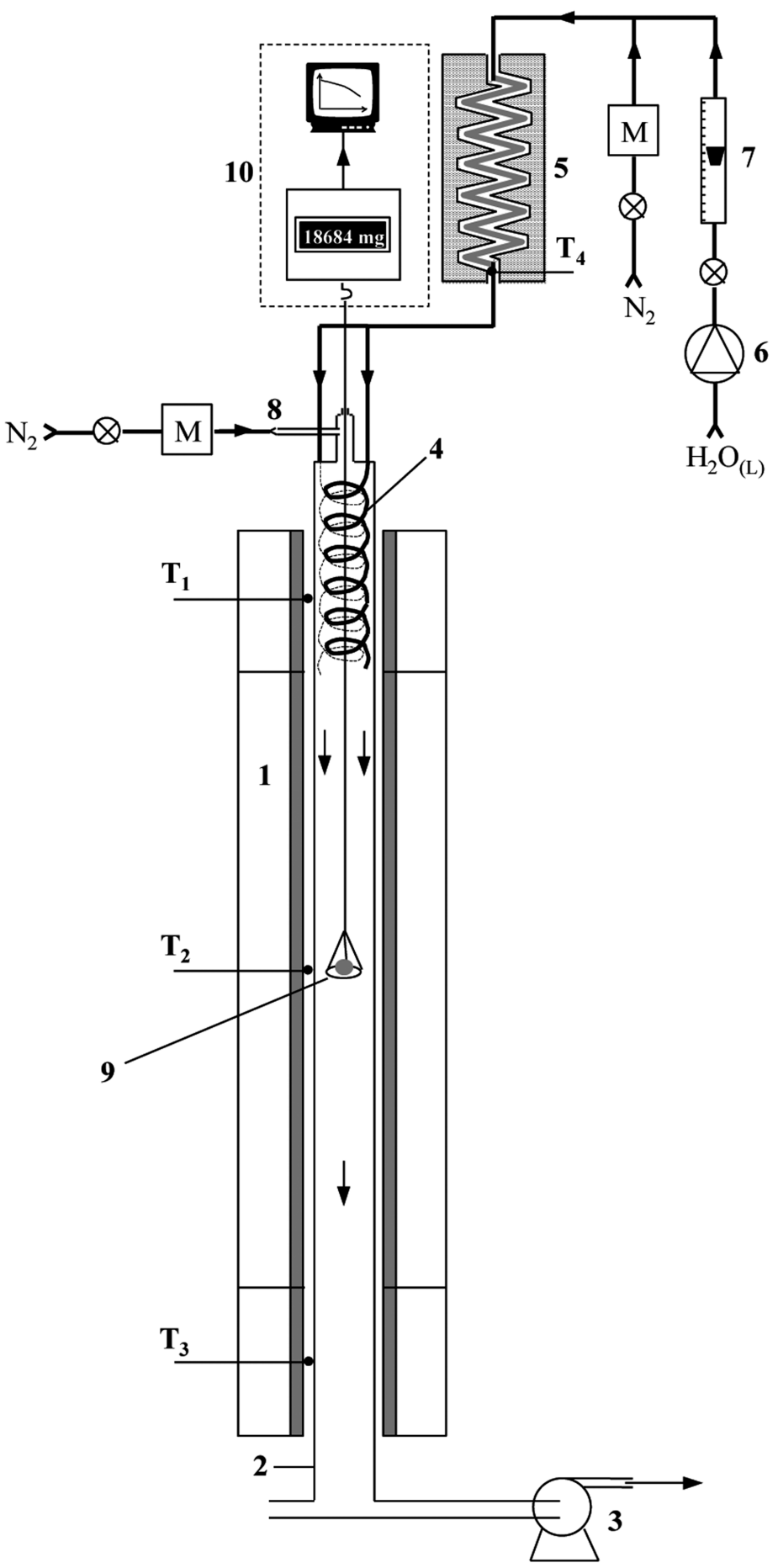

FIGURE 1 Macro thermogravimetry experimental apparatus. (1) Electric furnace; (2) Quartz tube; (3) Extractor; (4) Preheater; (5) Evaporator; (6) Water feeding system; (7) Water flow rate; (8) Leakage compensation; (9) Suspension basket; (10) Weighing system; $\left(T_{i}\right)$ Regulation thermocouples; $\left(M_{i}\right)$ Mass flow meter. 
TABLE 1

Proximate and Ultimate Analysis of Charcoal from Maritime Pine Wood Chips

\begin{tabular}{|c|c|c|c|c|c|c|c|c|}
\hline \multicolumn{4}{|c|}{ Proximate Analysis, Mass \% } & \multicolumn{5}{|c|}{ Ultimate Analysis, Mass \% } \\
\hline$M$ & $V M(d r y)$ & $F C(d r y)$ & Ash (dry) & $C \pm 0.3 \%$ & $H \pm 0.3 \%$ & $O \pm 0.3 \%$ & $N \pm 0.1 \%$ & $S \pm 0.005 \%$ \\
\hline 1.8 & 4.9 & 93.7 & 1.4 & 89.8 & 2.2 & 6.1 & 0.1 & 0.01 \\
\hline
\end{tabular}

M: Moisture content; VM: Volatile matter; FC: Fixed carbon.

$\mathrm{N}_{2}$ - at a controlled temperature. The particles are continuously weighed to monitor conversion of the charcoal.

The particles were left in the hot furnace swept by nitrogen and maintained until their weight stabilized, attesting to the removal of possible residual volatile matter or re-adsorbed species. The atmosphere then turned into a gasifying atmosphere, marking the beginning of the experiment.

\subsection{Preparation and Characterization of the Samples}

The material used in this study was charcoal from maritime pine wood chips. Charcoal was produced using a pilot scale screw pyrolysis reactor. The pyrolysis operating conditions were chosen to produce a char with high fixed carbon content, i.e., a temperature of $750^{\circ} \mathrm{C}$, a $1 \mathrm{~h}$ residence time, and $15 \mathrm{~kg} / \mathrm{h}$ of flow rate in a $200-\mathrm{mm}$ internal diameter electrically heated screw. Based on previous studies, the heating rate in the reactor was estimated to be $50^{\circ} \mathrm{C} / \mathrm{min}$ (Fassinou et al., 2009).

After pyrolysis, samples with a controlled particle size were prepared by sieving, and the thickness of particles was subsequently measured using an electronic calliper. Particles with a thickness of 1.5 and $5.5 \mathrm{~mm}$ were selected for all the experiments. Table 1 lists the results of proximate and ultimate analysis of the charcoal particles. The amount of fixed carbon was close to $90 \%$, attesting to the high quality of the charcoal. The amount of ash, a potential catalyzer, was $1.4 \%$.

\section{GASIFICATION OF CHARCOAL IN SINGLE ATMOSPHERES}

\subsection{Operating Conditions}

All experiments were carried out at a temperature of $900^{\circ} \mathrm{C}$ and at atmospheric total pressure. For each gasifying atmosphere, the mole fraction was chosen to cover values encountered in industrial reactors; experiments were performed at respectively 10,20, and 40\% mole fraction, respectively, for both $\mathrm{H}_{2} \mathrm{O}$ and $\mathrm{CO}_{2}$. In order to deal with the variability of the composition of biomass chips, each experiment was carried out with three to five particles in the grid basket. Care was taken to ensure there was no interaction between the particles. Each experiment was repeated at least three times.

\subsection{Results and Interpretations}

From the mass $m(t)$ at any time, the conversion progress $X$ was calculated according to Eq. (6):

$$
X(t)=\frac{m_{0}-m(t)}{m_{0}-m_{\text {ash }}},
$$



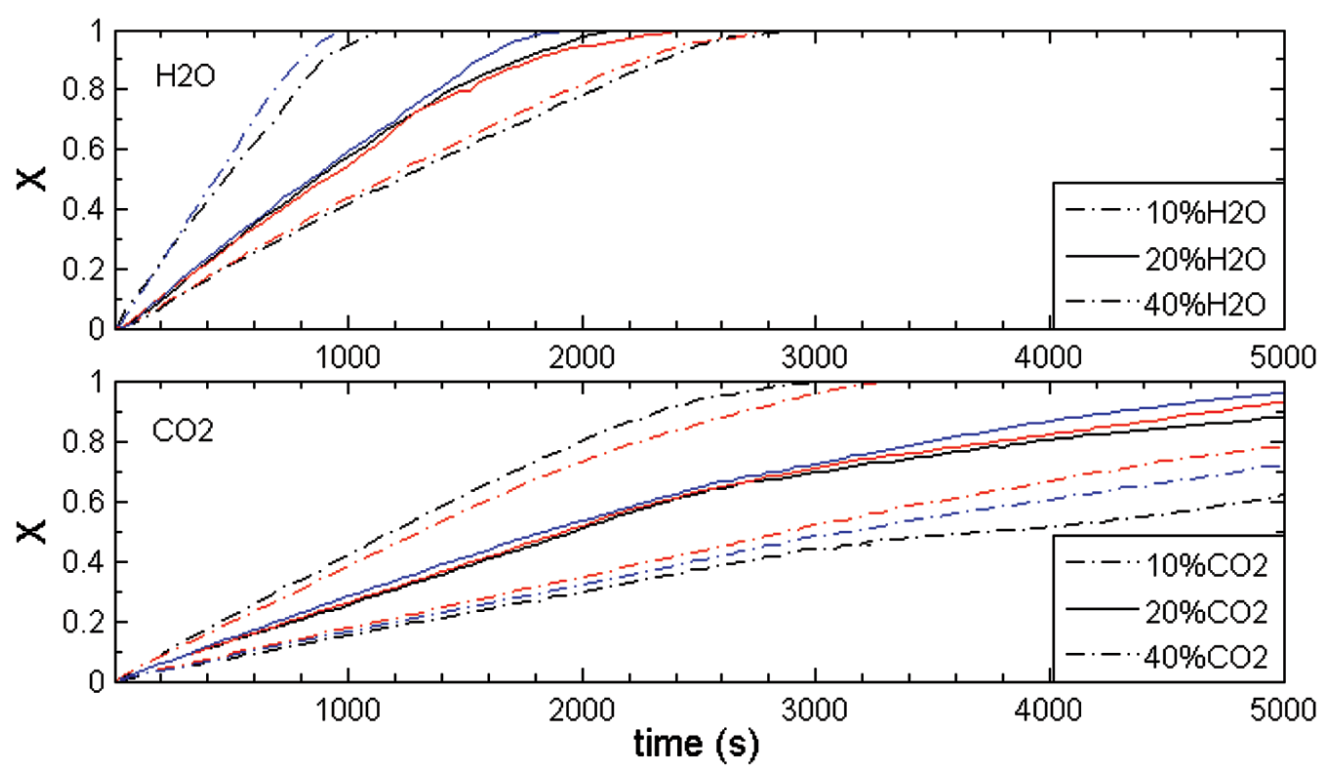

FIGURE 2 Conversion progress versus time during gasification at $900^{\circ} \mathrm{C}$ in single atmospheres $(10,20$, and $40 \% \mathrm{H}_{2} \mathrm{O}$ and 10,20 , and $40 \% \mathrm{CO}_{2}$ ). (color figure available online)

where $m_{0}$ and $m_{\text {ash }}$ represent, respectively, the initial mass of the char and the mass of ash at the end of the process. Figure 2 shows the conversion progress versus time for all the experiments.

For char- $\mathrm{H}_{2} \mathrm{O}$ experiments, good repeatability was observed. Before $50 \%$ conversion, dispersion was small $(<5 \%)$, while after $50 \%$ conversion, it could reach $10 \%$. An average gasification rate was calculated for each experiment at $X=0.5$ as $0.5 / t$ (in s $^{-1}$ ). It was 2.5 times larger in $40 \%$ steam than in $10 \%$ steam.

For char- $\mathrm{CO}_{2}$ experiments, much larger dispersion was observed. It is difficult to give an explanation for this result. The gasification rate was 2.4 times higher in $40 \% \mathrm{CO}_{2}$ than in $10 \%$ $\mathrm{CO}_{2}$. Moreover, the results revealed a strange evolution in $20 \% \mathrm{CO}_{2}$ : the reaction was considerably slowed down after $60 \%$ conversion. This was also observed by Standish and Tanjung (1988) during their experiments on gasification of charcoal particles in $\mathrm{CO}_{2}$ at a concentration of $20 \% \mathrm{CO}_{2}$.

At a given concentration (for instance 40\%) steam gasification was on average three times faster than $\mathrm{CO}_{2}$ gasification.

\subsection{Determination of Surface Functions (SF)}

In practice, the SF can be derived without using a model by plotting $R / R_{50}$ (where $R_{50}$ is the reactivity for $X=50 \%$ ). The reactivity $R$ was obtained by derivation of the $X$ curves. It was not possible to plot the values of SF when $X$ tends towards 1 because by the end of the experiment, the decrease in mass was very small leading to a too small signal/noise ratio to enable correct derivation of the signal and calculation of $R$. At the beginning of the experiments, the derivative was also too noisy for accurate determination. Thus, for small values of $X$ ranging from zero to $0.15, F(X)$ was assumed to be constant and equal to $F(X=0.15)$. In addition, from a theoretical point of view, $F(X)$ should be determined using intrinsic values of $R$, i.e., from experiments in which no limitation by heat or mass transfer occurs. In practice, it has been shown in the literature that experiments with larger particles can be used (Sorensen et al., 1996). It is shown in Figure 3 that the results obtained for small particles $(1.5 \mathrm{~mm}$ thickness $)$ were similar to those for larger particles (5.5 $\mathrm{mm}$ thickness). 


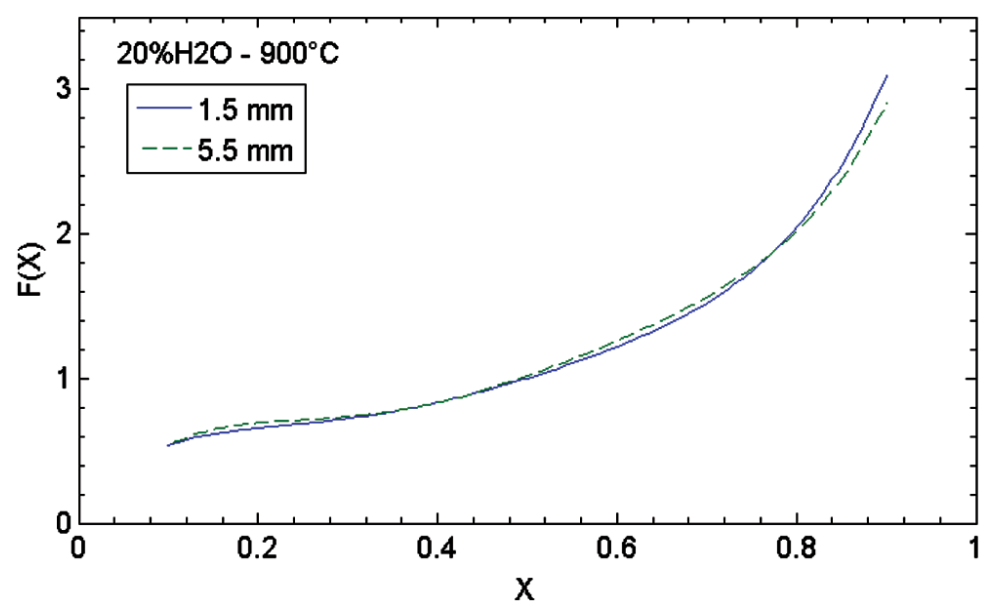

FIGURE $3 \mathrm{SF}$ for the two cases of $1.5 \mathrm{~mm}$ and $5.5 \mathrm{~mm}$ particles in steam atmosphere. (color figure available online)

All results are plotted as $F(X)$ versus $X$ in Figure 4 for the two reactant gases. For the atmospheres with 10 and $40 \% \mathrm{CO}_{2}$, it is interesting to note that good repeatability was obtained for the SF when the evolution of $X$ over time showed bad repeatability. While the reactivity of the three samples differed, the SF remained the same. Conversely, in $20 \% \mathrm{CO}_{2}$, the repeatability of the test appeared to be good in the $X=f(t)$ plot (Figure 2), but results led to quite different shapes for the SF after $60 \%$ conversion.

An average value for repeatability experiments was then determined and is plotted in Figure 5. From these results, polynomials were derived for $F(X)$, as shown in Table 2. It was clearly observed that the 5th order was the most suitable to fit simultaneously all the experimental results of $F(X)$ in the different atmospheres with the best correlation coefficients. The results show that except in $20 \% \mathrm{CO}_{2}$, the SF are monotonically increasing functions. For this representation, where the $\mathrm{SF}$ are normalized to 1 at $X=0.5$, the plots indicate a small increase (from 0.6 to 1 ) when $X$ increases from 0.1 to 0.5 , and a very strong increase (to 4 or 5 ) when $X$ tends towards 0.9 .

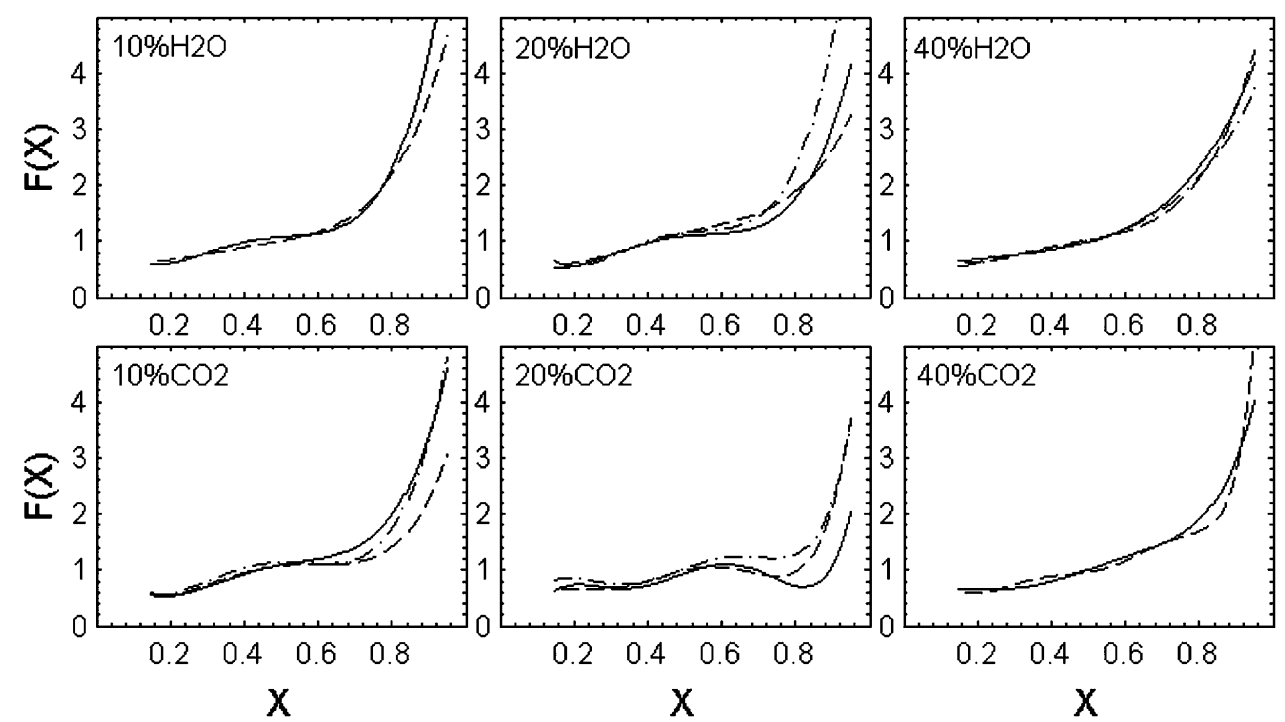

FIGURE 4 SF for each experimental result obtained in a single atmosphere. 


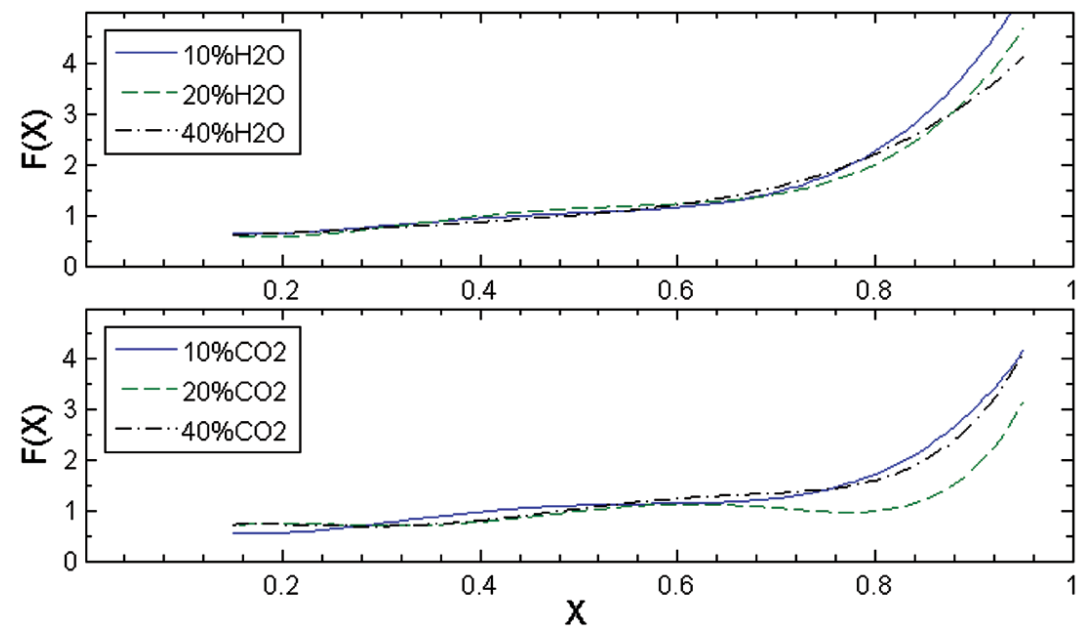

FIGURE 5 Average SF obtained in each single atmosphere. (color figure available online)

In experiments with 10,20 , and $40 \% \mathrm{H}_{2} \mathrm{O}$, the $\mathrm{SF}$ appeared not to be influenced by the concentration of steam. When $\mathrm{CO}_{2}$ was the gasifying agent, a strong influence of the concentration was observed, confirming the strange behavior observed in Figure 2 in $20 \% \mathrm{CO}_{2}$. The function for $10 \% \mathrm{CO}_{2}$ was similar to that of $\mathrm{H}_{2} \mathrm{O}$ (whatever the concentration).

A decreasing SF was found with $20 \% \mathrm{CO}_{2}$ for $X$ between 0.6 and 0.75 . This evolution has never previously been reported in the literature. Referring to the discussion about the phenomena that are taken into account in the SF, it is not possible to attribute this irregular shape to a physical phenomenon.

Figure 6 plots several SF from the literature, normalized at $X=0.5$ to enable comparison. Expressions, such as $\alpha$-order of $(1-X)$, and polynomial forms commonly used for biomass were retained. The SF obtained in $10 \% \mathrm{H}_{2} \mathrm{O}$, which is similar to that obtained in $40 \% \mathrm{CO}_{2}$, has been added in the figure. It can be observed that up to $50 \%$ conversion, most of the SF published in the literature are similar. At higher conversions, all SF follow an exponential type function, but differ significantly in their rate of increase. The results of the authors' experiments $\left(10 \% \mathrm{H}_{2} \mathrm{O}\right)$ are within the range of values reported in the literature.

\section{GASIFICATION OF CHARCOAL IN $\mathrm{H}_{2} \mathrm{O}+\mathrm{CO}_{2}$ ATMOSPHERES}

To investigate mixed atmospheres, experiments were conducted using $20 \% \mathrm{H}_{2} \mathrm{O}$ with the addition of alternatively 10, 20, and $40 \% \mathrm{CO}_{2}$. The results of conversion versus time are plotted in Figure 7.

TABLE 2

Surface Function Expressions Derived for Different Atmospheres

\begin{tabular}{lc}
\hline Atmosphere & Surface Functions $(S F)$ \\
\hline $\mathrm{H}_{2} \mathrm{O}$ & $F(X)=64.16 X^{5}-128.12 X^{4}+94.35 X^{3}-29.39 X^{2}+4.51 X+0.20$ \\
$\mathrm{CO}_{2}$ & \\
$10 \%$ & $F(X)=95.59 X^{5}-199.69 X^{4}+156.39 X^{3}-53.82 X^{2}+8.51 X+0.18$ \\
$20 \%$ & $F(X)=90.90 X^{5}-187.23 X^{4}+135.12 X^{3}-40.59 X^{2}+5.55 X+0.35$ \\
$40 \%$ & $F(X)=70.78 X^{5}-159.95 X^{4}+132.39 X^{3}-46.19 X^{2}+6.53 X+0.35$ \\
$\mathrm{H}_{2} \mathrm{O}+\mathrm{CO}_{2}$ & $F(X)=130.14 X^{5}-264.67 X^{4}+192.38 X^{3}-57.90 X^{2}+7.28 X+0.25$ \\
\hline
\end{tabular}




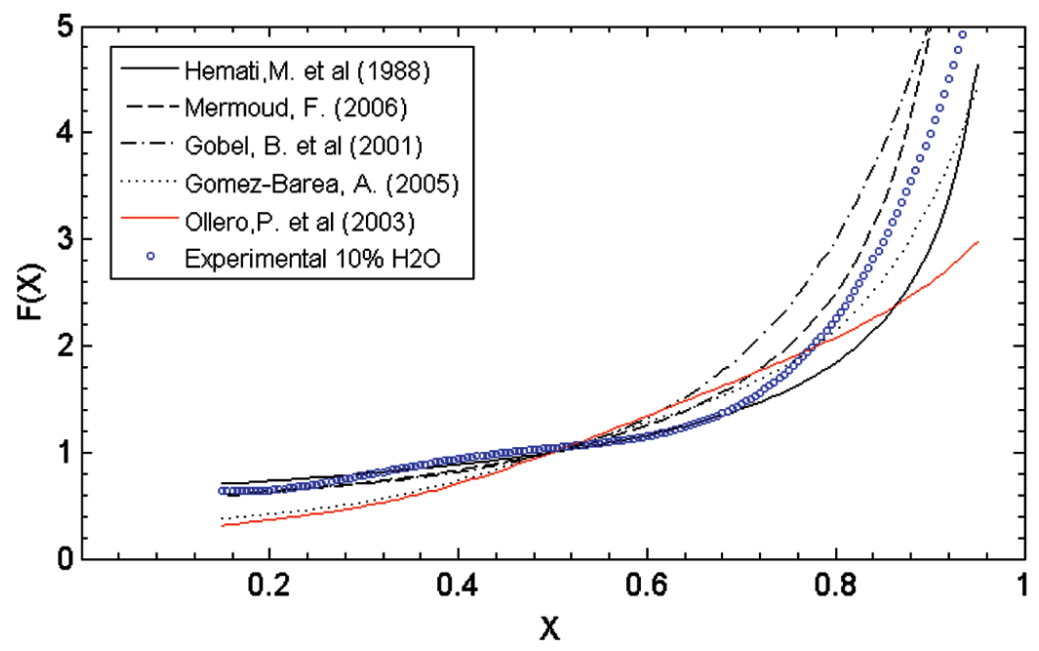

FIGURE 6 SF for biomass gasification published by several authors, normalized by $F(X=0.5)$ compared to the average $\mathrm{SF}$ for gasification in $10 \% \mathrm{H}_{2} \mathrm{O}$. (color figure available online)

For each mixed atmosphere, the average results obtained in the single atmospheres are given as references. Rather good repeatability was observed. It can be seen that adding $\mathrm{CO}_{2}$ to $\mathrm{H}_{2} \mathrm{O}$ accelerated steam gasification. Indeed, mixing, respectively, 10, 20, and $40 \%$ of $\mathrm{CO}_{2}$ with $20 \%$ of $\mathrm{H}_{2} \mathrm{O}$ increased the rate of gasification by 20,33 , and $57 \%$, respectively, compared to the rate of gasification in $20 \% \mathrm{H}_{2} \mathrm{O}$ alone. This is a new result, since in the literature, studies on biomass gasification concluded on that steam gasification was inhibited by $\mathrm{CO}_{2}(\mathrm{Ollero}$ et al., 2003).
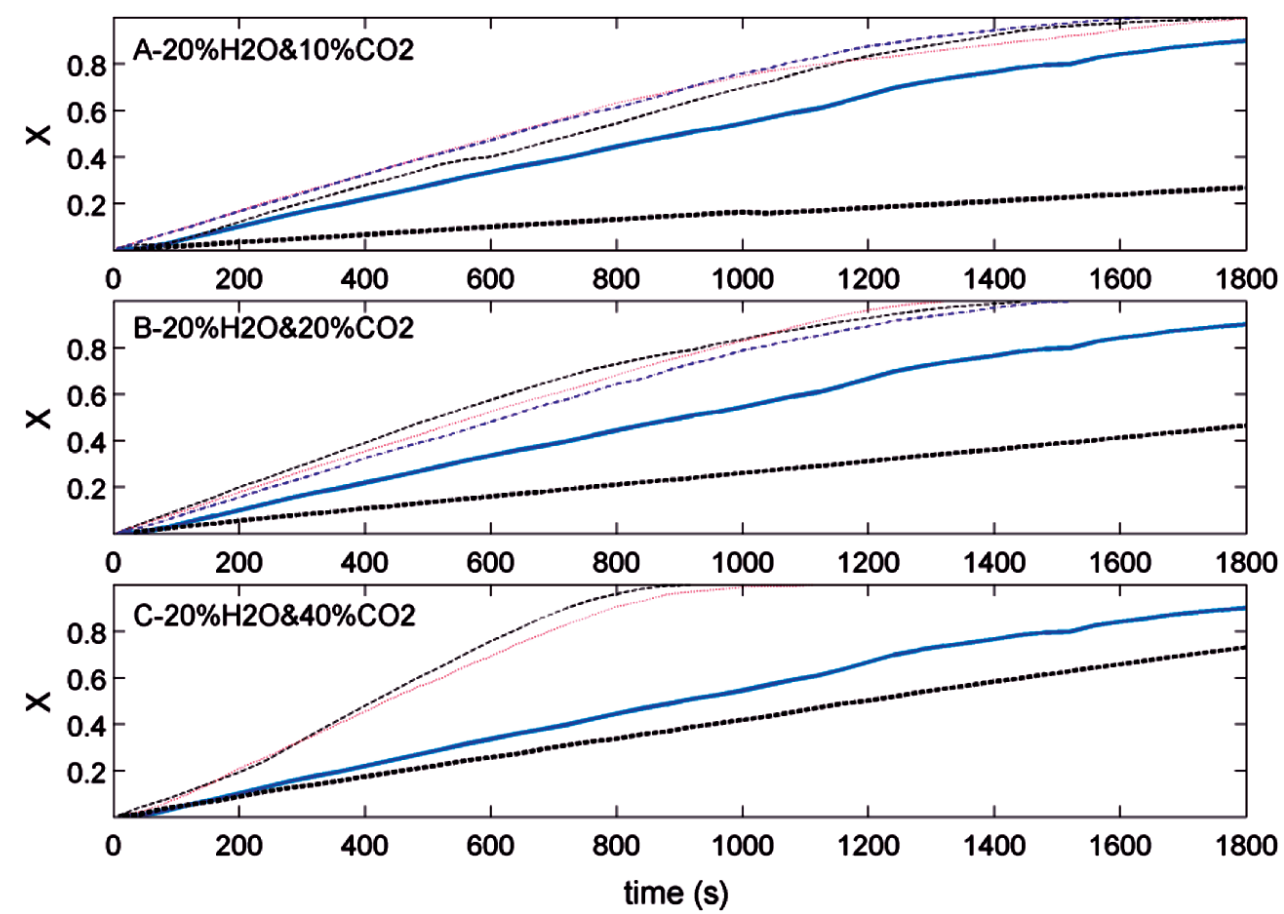

FIGURE 7 Experimental results obtained in mixed atmospheres (A: $10 \% \mathrm{H}_{2} \mathrm{O}$ and $20 \% \mathrm{CO}_{2} ; \mathrm{B}: 20 \% \mathrm{H}_{2} \mathrm{O}$ and $20 \% \mathrm{CO}_{2}$; and $\mathrm{C}: 20 \% \mathrm{H}_{2} \mathrm{O}$ and $40 \% \mathrm{CO}_{2}$ ). For each mixed atmosphere, the corresponding average experimental results for single atmospheres are shown in thick solid line $\left(20 \% \mathrm{H}_{2} \mathrm{O}\right.$ single atmosphere) and in thick dashed lines $\left(\mathrm{CO}_{2}\right.$ single atmospheres). (color figure available online) 
In the $20 \% \mathrm{H}_{2} \mathrm{O}+10 \% \mathrm{CO}_{2}$ atmosphere, the average gasification rate was $0.74510^{-3} \mathrm{~s}^{-1}$, which is approximately equal to the sum of the gasification rates obtained in the two separate atmospheres: $0.74010^{-3} \mathrm{~s}^{-1}$. This was also the case for the mixed atmosphere $20 \% \mathrm{H}_{2} \mathrm{O}+20 \%$ $\mathrm{CO}_{2}$. In the $20 \% \mathrm{H}_{2} \mathrm{O}+40 \% \mathrm{CO}_{2}$ atmosphere, the average gasification rate was $1.1910^{-3} \mathrm{~s}^{-1}$, i.e., $20 \%$ higher than the sum of the gasification rates obtained in the two single atmospheres. In other words, cooperation between $\mathrm{CO}_{2}$ and $\mathrm{H}_{2} \mathrm{O}$ led to unexpected behaviors. A number of considerations can help interpret this result.

First, the geometrical structure of the two molecules-polar and non-linear for $\mathrm{H}_{2} \mathrm{O}$ and linear and apolar for $\mathrm{CO}_{2}$ - predestines them to different adsorption mechanisms on potentially different active carbon sites (Slasli et al., 2004).

The presence of hydrophilic oxygen, such as [-O], at the surface of char leads to the formation of hydrogen bonds, which could hinder $\mathrm{H}_{2} \mathrm{O}$ adsorption and favor that of $\mathrm{CO}_{2}$ (Stoeckli et al., 2002). In the same way, as it is a non-organic molecule, $\mathrm{H}_{2} \mathrm{O}$ can only access hydrophobic sites while $\mathrm{CO}_{2}$, which is an organic molecule, can access both hydrophilic and hydrophobic sites.

According to Stoeckli et al. (2002), due to constriction or molecular sieve effects, $\mathrm{CO}_{2}$ molecules have access to micropores of materials while those of $\mathrm{H}_{2} \mathrm{O}$, which are assumed to be bigger, do not.

For one of the previous reasons or for any other reason, $\mathrm{CO}_{2}$ molecules can access internal micropores more easily than $\mathrm{H}_{2} \mathrm{O}$ molecules, and can therefore open certain pores, making them accessible to $\mathrm{H}_{2} \mathrm{O}$ molecules.

The assumption that $\mathrm{H}_{2} \mathrm{O}$ and $\mathrm{CO}_{2}$ molecules reacted with different sites and that no competition occurred is not sufficient to explain the increase of $20 \%$ in the gasification rate under mixed atmospheres. Point 0 can be proposed as an explanation, but a more precise explanation requires further research work.

Roberts and Harris (2007) recently concluded that $\mathrm{CO}_{2}$ has an inhibitory effect on $\mathrm{H}_{2} \mathrm{O}$ gasification, in contradiction to the authors' results. It is believed that the conclusions of Roberts and Harris (2007) are valid in their experimental conditions only, and with a little hindsight may be called into question.

Figure 8 gives the plots of SF obtained with the three mixed atmospheres and for all repeatability tests. Again, the repeatability of experiments was excellent until $X=0.6$; this attests to the good quality of experiments and confirms that the variations in SF after $60 \%$ conversion are due to specific phenomena.

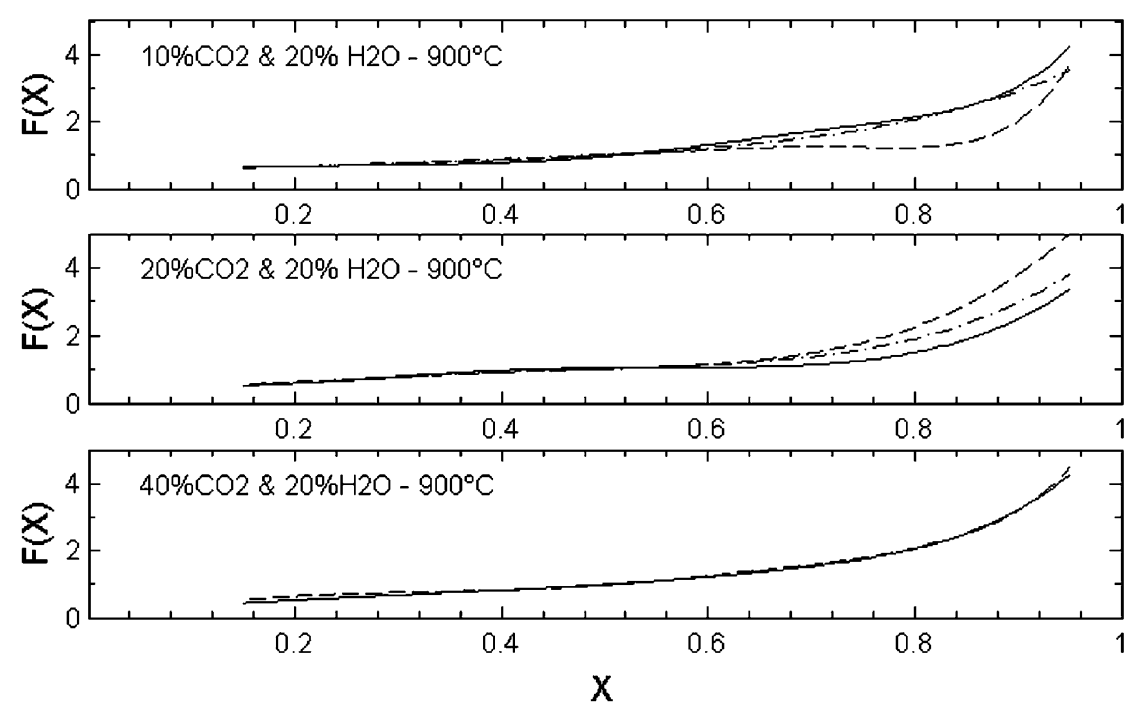

FIGURE 8 SF obtained in different mixed atmospheres for all experimental repeatability tests. 


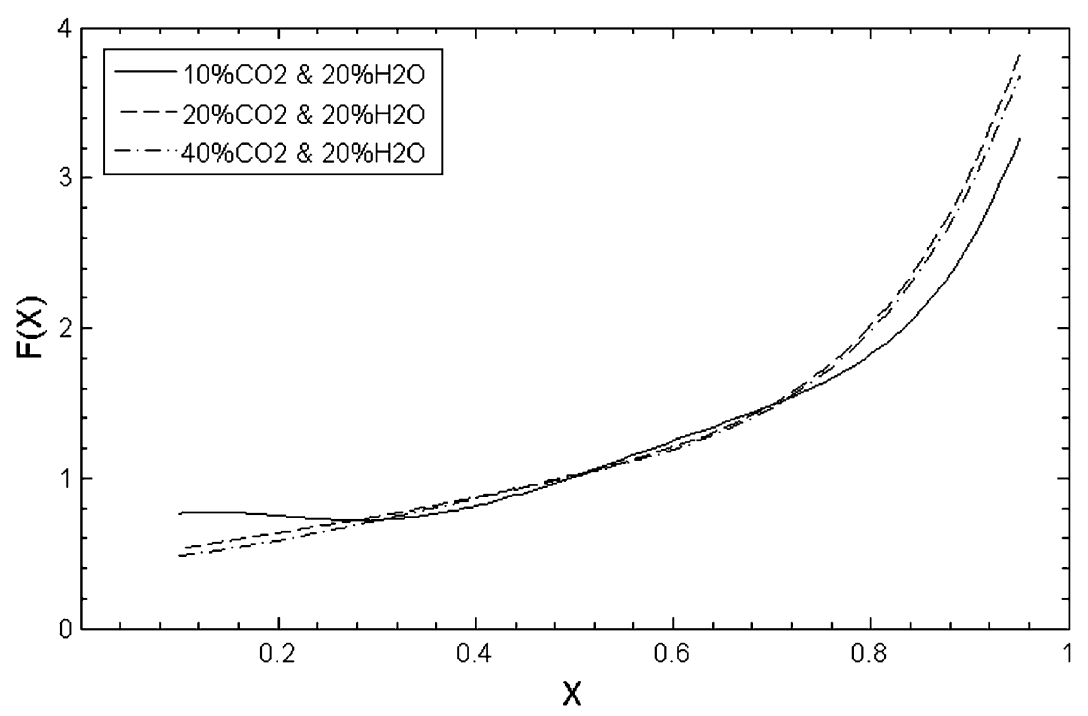

FIGURE 9 Average SF obtained in the different mixed atmospheres.

Figure 9 compares all the average SF obtained in mixed atmosphere. From these curves, it can be seen that the curve is similar when the amount of $\mathrm{CO}_{2}$ was modified from 10 to $40 \%$. Thus, an average 5th-order polynomial expression for mixed atmosphere is given in Eq. (7):

$$
F(X)=130.14 X^{5}-264.67 X^{4}+192.38 X^{3}-57.90 X^{2}+7.28 X+0.25 .
$$

\section{CONCLUSION}

The gasification of wood char particles during gasification in three atmospheres, i.e., $\mathrm{H}_{2} \mathrm{O}, \mathrm{CO}_{2}$, and $\mathrm{H}_{2} \mathrm{O} / \mathrm{CO}_{2}$, was experimentally investigated. The formulation adopted enables to split the reactivity $R(t)$ into kinetic parameters, $r_{j}$, and all physical aspects, i.e., reactive surface evolution, thermal annealing, catalytic effects, into a surface function SF, $F(X)$, as follows:

$$
\frac{d m(t)}{d t}=-R(t) \cdot m(t) \quad \text { with } \quad R(t)=F(X(t)) \cdot r_{j}(T \cdot p) .
$$

The repeatability of the derived SF was always very good until $X=0.6$, which attests to the good quality of the experiments. For higher values of $X$, significant dispersion was observed, despite the use of several particles for each experiment. The SF depends on the nature of the reactant gas, and-in the case of $\mathrm{CO}_{2}-$ on the concentration of the gas. A SF that surprisingly decreased with increasing $X$ in the range $0.6-0.75$ was obtained with $\mathrm{CO}_{2}$ atmosphere in this work.

An important result of this article is that the addition of $\mathrm{CO}_{2}$ in a $\mathrm{H}_{2} \mathrm{O}$ atmosphere led to an acceleration of gasification kinetic. In a mixture of $20 \% \mathrm{H}_{2} \mathrm{O}$ and $40 \% \mathrm{CO}_{2}$, the gasification rate was $20 \%$ higher than the sum of the gasification rates in the two single atmospheres.

\section{REFERENCES}

Commandré, J. M., Stanmore, B. R., and Salvador, S. 2002. The high temperature reaction of carbon with nitric oxide. Combus. \& Flame 128:211-216. 
Fassinou, W. F., Van de Steene, L., Toure, S., Volle, G., and Girard, P. 2009. Pyrolysis of Pinus pinaster in a two-stage gasifier: Influence of processing parameters and thermal cracking of tar. Fuel Proc. Technol. 90:75-90.

Gobel, B., Henriksen, U., Qvale, B., and Houbak, N. 2001. Dynamic modelling of char gasification in a fixed-bed. In: Progress in Thermochemical Biomass Conversion. London: Blackwell, pp. 92-108.

Mermoud, F., Salvador, S., Van de steene, L., and Golfier, F. 2006. Influence of the pyrolysis heating rate on the steam gasification rate of large wood char particles. Fuel 85:1473-1482.

Ollero, P., Serrera, A., Arjona, R., and Alcantarilla, S. 2003. The $\mathrm{CO}_{2}$ gasification kinetics of olive residue. Biomass \& Bioenergy 24:151-161.

Roberts, D. G., and Harris, D. J. 2006. A kinetic analysis of coal char gasification reactions at high pressures. Energy Fuels 20:2314-2320.

Roberts, D. G., and Harris, D. J. 2007. Char gasification in mixtures of $\mathrm{CO}_{2}$ and $\mathrm{H}_{2} \mathrm{O}$ : Competition and inhibition. Fuel $86: 2672-2678$

Slasli, A. M., Jorge, M., Stoeckli, F., and Seaton, N. A. 2004. Modelling of water adsorption by activated carbons: Effects of microporous structure and oxygen content. Carbon 42:1947-1952.

Sorensen, L. H., Gjernes, E., Jessen, T., and Fjellerup, J. 1996. Determination of reactivity parameters of model carbons, cokes and flame-chars. Fuel 75:31-38.

Standish, N., and Tanjung, A. F. A. 1988. Gasification of single wood charcoal particles in $\mathrm{CO}_{2}$. Fuel 67:666-672.

Stoeckli, F., Slasli, A., Hugi-Cleary, D., and Guillot, A. 2002. The characterization of microporosity in carbons with molecular sieve effects. Micropor. \& Mesopor. Mater. 51:197-202. 